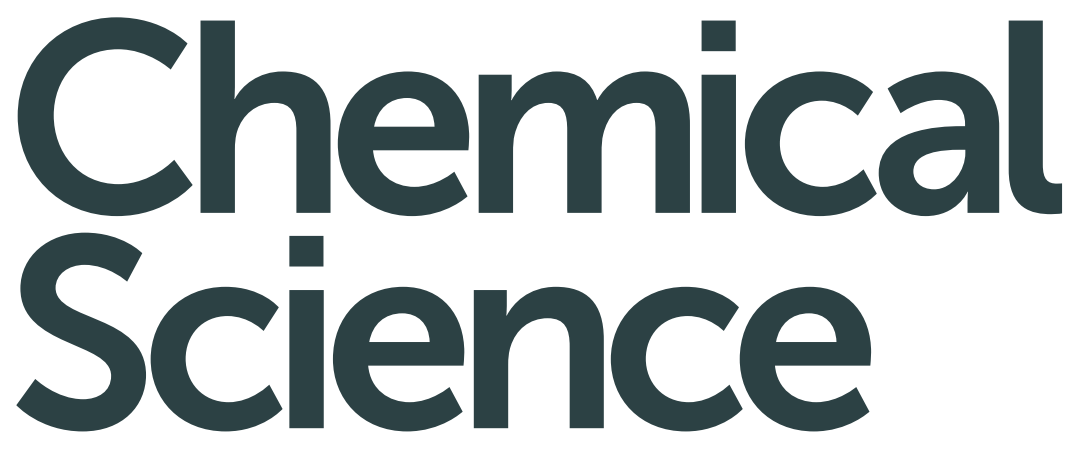

rsc.li/chemical-science

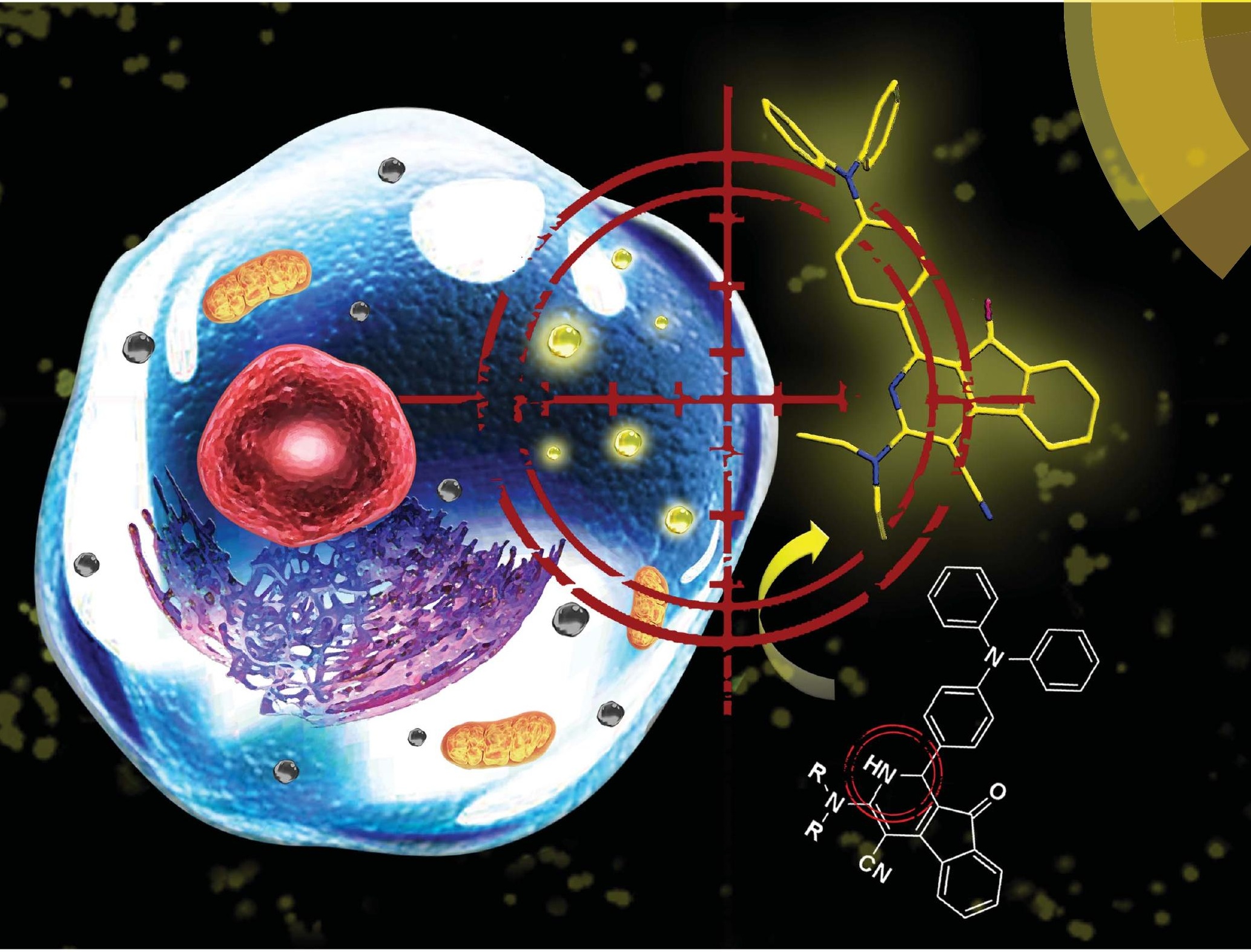

ISSN 2041-6539

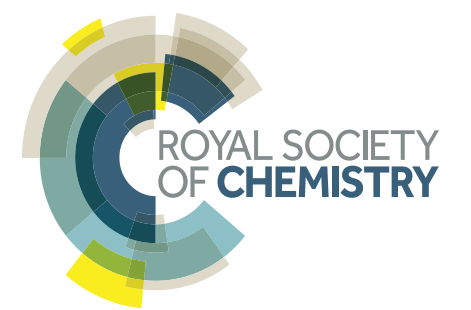




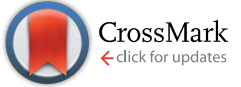

Cite this: Chem. Sci., 2017, 8, 1763

\title{
Photoactivatable aggregation-induced emission probes for lipid droplets-specific live cell imaging $†$
}

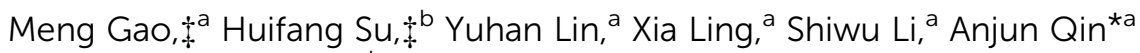 \\ and Ben Zhong Tang ${ }^{\star a b}$
}

Photoactivatable probes for lipid droplets (LDs)-specific live-cell imaging are powerful tools for investigating their biological functions through precise spatial and temporal control. Ideal photoactivatable probes for LDs imaging require high concentration accumulation of fluorophores in LDs, simple synthetic procedures, and excellent photoactivation efficiency. However, it is difficult to overcome these challenges by conventional fluorophores due to aggregation-caused quenching (ACQ). In this study, a new class of photoactivatable and LDs-specific fluorescent probes was developed based on dihydro-2-azafluorenones, which can easily undergo photooxidative dehydrogenation reaction to afford 2-azafluorenones with aggregation-induced emission (AIE) properties. Dihydro-2-azafluorenones as photoactivatable and LDs-specific probes display significant advantages of excellent photoactivation efficiency and lack of self-quenching in the aggregated state, and are expected to have broad applications in study of biological functions of LDs' through light-controlled spatiotemporal imaging.

Received 1st November 2016 Accepted 20th December 2016

DOI: $10.1039 / \mathrm{c} 6 \mathrm{sc} 04842 \mathrm{k}$

www.rsc.org/chemicalscience convenient for operation than fluorescent proteins, have not been reported in the literature.

To achieve the photoactivatable fluorescent imaging of LDs, two major challenges need to be overcome. First, fluorophores should selectively accumulate in LDs at high concentration to emit bright fluorescence with a high signal-to-noise ratio; however, this is difficult for conventional fluorophores due to aggregation-caused quenching (ACQ). ${ }^{6}$ Second, photoactivatable probes are required to achieve light-controlled spatiotemporal imaging of LDs, but previously reported photoactivatable probes suffer from limited light-up mechanisms, complicated synthetic procedures, generation of toxic byproducts, and difficulty to specifically accumulate in LDs. ${ }^{7}$ Although several LDs-specific fluorescent dyes, such as Nile Red, BODIPY493/503 green, monodansylpentane, AFN, NPBDP, LipidTOX red, and LD540, have been developed, the lack of photoactivatable ability and self-quenching at high concentration have severely limited their applications. ${ }^{8}$

Recently, aggregation-induced emission (AIE) has been proposed as a fundamental solution to solve the fluorescence self-quenching problem in the aggregated state. ${ }^{9}$ The AIE lightup mechanism has been proven to arise from the restriction of intramolecular motion. ${ }^{10}$ AIE-based bioprobes have unique advantages in terms of superior brightness, long-term in situ retention ability, high photostability, and low cytotoxicity. ${ }^{\mathbf{1 1}} \mathrm{We}$ have recently developed several AIEgens, including TPE-AmAl, TPE-AC, FAS, and DPAS, for LDs-specific imaging with the advantages of absence of self-quenching and easily adjustable emission spectra. ${ }^{12}$ However, it is difficult to introduce photoresponsive groups into these classic AIEgens. Therefore, 

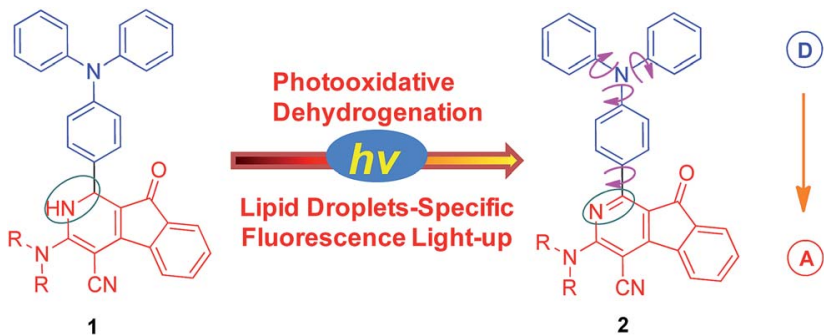

Scheme 1 Photooxidative dehydrogenation of dihydro-2-azafluorenone 1 to afford 2-azafluorenone 2 with AlE properties.

LDs-specific probes based on a new class of AIEgens with easy availability and excellent photoactivation efficiency are highly required to explore the biological functions of LDs.

2-Azafluorenones are traditionally studied as core structures in many biologically active molecules; however, their photophysical properties and bioimaging applications have been rarely investigated. ${ }^{13}$ Unexpectedly, we found that 2-azafluorenone 2 can emit strong fluorescence in the aggregated state with typical AIE properties via the restriction of intramolecular motion and twisted intramolecular charge transfer (TICT) mechanisms (Scheme 1). Moreover, we found that dihydro-2-azafluorenone 1 can be efficiently transformed into 2-azafluorenone 2 via photooxidative dehydrogenation reaction and can be used for LDs-specific imaging with an excellent photoactivation efficiency.

\section{Experimental section}

General procedures for the synthesis of compounds 1 and 2 (1a and 2a are presented as an example)

Synthesis of 1a. BDOYM (225 mg, $0.5 \mathrm{mmol})$ and morpholine (43.5 mg, $0.5 \mathrm{mmol}$ ) were first dissolved in MeCN $(10 \mathrm{~mL})$. The mixture was stirred at $50{ }^{\circ} \mathrm{C}$ under nitrogen for $12 \mathrm{~h}$. After cooling down to room temperature, the reaction mixture was dried under reduced pressure. The residue was further separated by column chromatography (silica, petroleum ether : ethyl acetate $=5: 1$ ) to give $1 \mathrm{a}$ as a red solid $(126 \mathrm{mg}$, $47 \%$ yield).

Synthesis of 2a. BDOYM (225 mg, $0.5 \mathrm{mmol})$ and morpholine (43.5 mg, $0.5 \mathrm{mmol}$ ) were first dissolved in MeCN (10 mL). The mixture was stirred at reflux temperature under dry air and irradiation with a $7 \mathrm{~W}$ fluorescent bulb for $12 \mathrm{~h}$. After cooling down to room temperature, the reaction mixture was dried under reduced pressure. The residue was further separated by column chromatography (silica, petroleum ether : ethyl acetate $=8: 1)$ to give $1 \mathrm{a}$ as an orange red solid (162 $\mathrm{mg}, 61 \%$ yield).

\section{Cell cultures}

HCC827, A549, and HLF cell lines were purchased from ATCC. HCC827 cells were cultured in RPMI-1640 with $1 \%$ penicillinstreptomycin and $10 \% \mathrm{FBS}$ at $37^{\circ} \mathrm{C}$ in a humidified incubator with $5 \% \mathrm{CO}_{2}$. A549 and HLF cells were cultured in DMEM with $1 \%$ penicillin-streptomycin and $10 \%$ FBS at $37{ }^{\circ} \mathrm{C}$ in a humidified incubator with $5 \% \mathrm{CO}_{2}$. The culture medium was changed every other day and the cells were collected by treating with $0.25 \%$ trypsin-EDTA solution after they reached confluence.

\section{Cell viability}

HCC827, A549, and HLF cells were respectively seeded in 96-well plates at a density of $5 \times 10^{4}$ cells per mL. After $24 \mathrm{~h}$ of culture, different concentrations of $\mathbf{1}$ or $\mathbf{2}$ were added and further incubated for $24 \mathrm{~h}$. The sample and control wells were washed twice with PBS buffer and added with freshly prepared MTT medium solution $\left(0.5 \mathrm{mg} \mathrm{mL}{ }^{-1}, 100 \mu \mathrm{L}\right)$. After $3 \mathrm{~h}$ of incubation at $37^{\circ} \mathrm{C}$, the MTT medium solution was carefully removed and washed twice with PBS buffer. DMSO $(100 \mu \mathrm{L})$ was then added into each well and the plate was gently stirred for $10 \mathrm{~min}$ at room temperature to dissolve all the precipitates that were formed. The absorbance of sample and control wells at $570 \mathrm{~nm}$ was then measured by a microplate reader. Cell viability was then calculated by the ratio of the absorbance of the sample wells to control cells.

\section{Cell imaging}

Cells were grown in a $35 \mathrm{~mm}$ Petri dish with a coverslip at $37^{\circ} \mathrm{C}$. After incubation with $1(20 \mu \mathrm{M})$ for $15 \mathrm{~min}$, the cells were washed with PBS for three times. The photoactivated images were obtained using a confocal microscope via increasing scans at $405 \mathrm{~nm}$ with $1 \%$ laser power (the scanning rate was $22.4 \mathrm{~s}$ per frame). For 1a, the emission filter was $438-604 \mathrm{~nm}$; for $\mathbf{1 b}$, the emission filter was 515-690 nm; and for 1c, the emission filter was $551-675 \mathrm{~nm}$.

\section{Confocal co-localization}

For co-staining with lipid dye BODIPY493/503 green, cells were first incubated with probe $1(20 \mu \mathrm{M})$ and BODIPY493/503 green $(100 \mathrm{nM})$ at $37^{\circ} \mathrm{C}$ for $15 \mathrm{~min}$. The medium was then removed and the cells were rinsed with PBS for three times, and then imaged using a confocal microscope. For probe 1, the fluorescence was first photoactivated by irradiation at $405 \mathrm{~nm}(1 \%$ laser power) for designed time intervals, and then the fluorescence images were obtained. For 1a, the emission filter was 572-607 nm; for $1 \mathrm{~b}$, the emission filter was $572-689 \mathrm{~nm}$; and for 1c, the emission filter was $572-675 \mathrm{~nm}$; for BODIPY493/503 green, the excitation was $488 \mathrm{~nm}$ and the emission filter was $510-553 \mathrm{~nm}$.

\section{Spatially and temporally controlled cell imaging}

The observation window containing multicells was first imaged under irradiation at $405 \mathrm{~nm}(0.2 \%$ power $)$. The selected cells were then irradiated in a bleach model with $405 \mathrm{~nm}$ laser $(0.2 \%$ power) for 20 scans (the scanning rate was $22.4 \mathrm{~s}$ per frame). Subsequently, the whole observation window was imaged under irradiation at $405 \mathrm{~nm}(0.2 \%$ power). This process was repeated until all the selected cells in the observation window were lit-up. 


\section{Results and discussion}

We first established an efficient and direct method for preparing dihydro-2-azafluorenone 1 through a one-step reaction from easily available 2-((Z)-2-(4-(diphenylamino)benzylidene)-1,2-dihydro-1-oxoinden-3-ylidene)malononitrile (BDOYM) and amines, including morpholine, diethylamine, and ammonia solution (Fig. 1A). We also found that 2-azafluorenone 2 can be directly obtained from BDOYM and amines under light irradiation ( $7 \mathrm{~W}$ fluorescent bulb) and using air as the oxidant (for proposed reaction mechanism, see Scheme S1 in the ESI $\dagger$ ). Structures of all obtained compounds were elucidated by NMR spectroscopy and high-resolution mass spectrometry (Fig. S1-S6 $\dagger$ ). The structure of compound $2 \mathbf{b}$ was also verified by single crystal X-ray diffraction (Fig. 1B and C). ${ }^{\mathbf{1 4}}$ In the crystal of $\mathbf{2} \mathbf{b}$, the dihedral angle between the planar 2-azafluorenone ring and the 1-linked phenyl ring was $41.9(6)^{\circ}$, whereas the triphenylamine moiety exhibited a propeller conformation with dihedral angles of $61.3(2)^{\circ}, 67.9(1)^{\circ}$, and $73.3(6)^{\circ}$ between the aryl rings, respectively. This kind of conformation can contribute to the non-irradiative release of energy in solution via intramolecular rotation. In the crystal packing structure, various intermolecular $\mathrm{C}-\mathrm{H} \cdots \pi, \mathrm{C}-\mathrm{H} \cdots \mathrm{O}$, and van der Waals interactions were observed, which can help to restrict the intramolecular motion and block the non-radiative release of energy in the aggregated state.

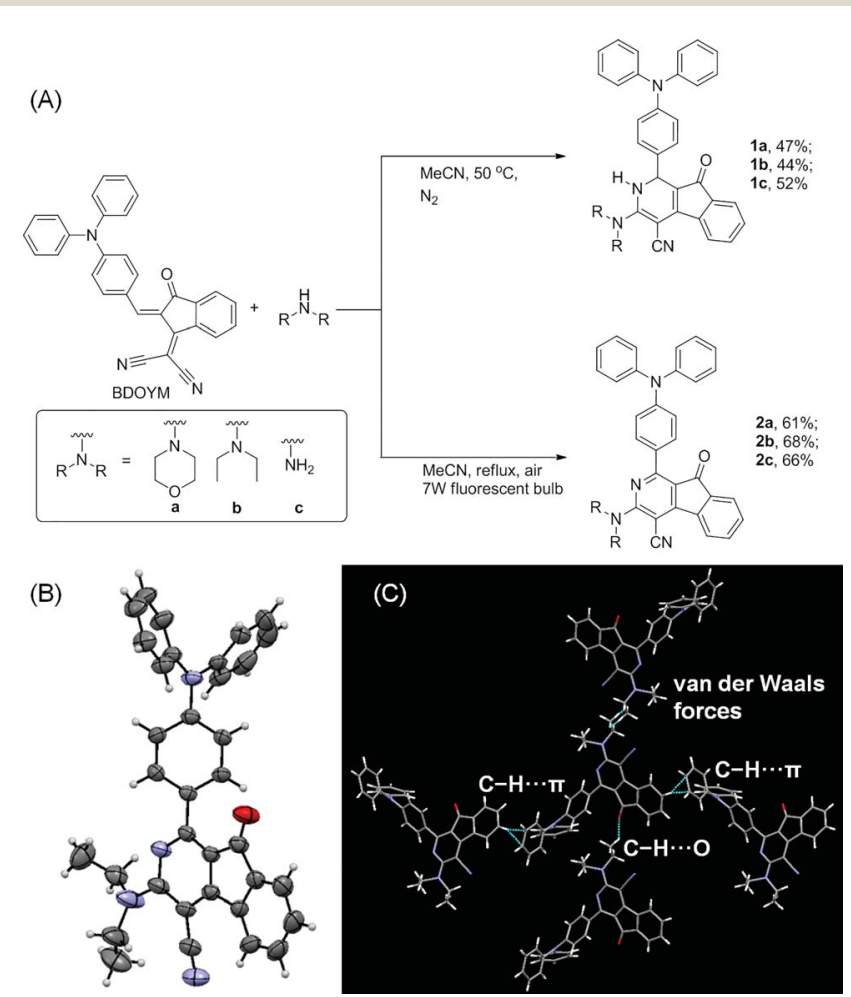

Fig. 1 (A) Synthetic routes for dihydro-2-azafluorenone 1 and 2azafluorenone 2. (B) Oak ridge thermal ellipsoid plot program (ORTEP) drawing of $2 \mathrm{~b}$. (C) Crystal packing structure of $2 \mathrm{~b}$. Intermolecular $\mathrm{C}-$ $\mathrm{H} \cdots \pi, \mathrm{C}-\mathrm{H} \cdots \mathrm{O}$, and van der Waals interactions are shown in green dashed lines.
Intrigued by the increased fluorescence intensity of 2 during drying on thin-layer chromatography (TLC) plates, we first examined their photophysical properties. For compound 2a, an absorption peak at $409 \mathrm{~nm}$ and a weak emission peak at $624 \mathrm{~nm}$ were observed in dilute THF solution (Fig. 2). In the THF/water mixture, its emission first underwent quenching from water fraction $\left(f_{\mathrm{w}}\right)=10$ to $70 \%$, and this phenomenon probably originated from the twisted internal charge transfer (TICT) effect, ${ }^{15}$ which was verified by the red-shifted and decreased emission of $\mathbf{2 a}$ with the increasing solvent polarity (Fig. S7†). Density functional theory based calculation of $2 \mathbf{a}$ also verified its typical donor-acceptor structural feature (Fig. S8†). The highest occupied molecular orbital (HOMO) of 2a is localized on the triphenylamine moiety, whereas the lowest unoccupied molecular orbital (LUMO) is localized on the 2-azafluorenone moiety. Interestingly, further increase in the water fractions $\left(f_{\mathrm{w}}\right)$ from 70 to $90 \%$ led to a significant emission enhancement, which can be due to the formation of aggregates of $2 \mathrm{a}$ caused by the poor solvating ability of THF/water mixture with high water
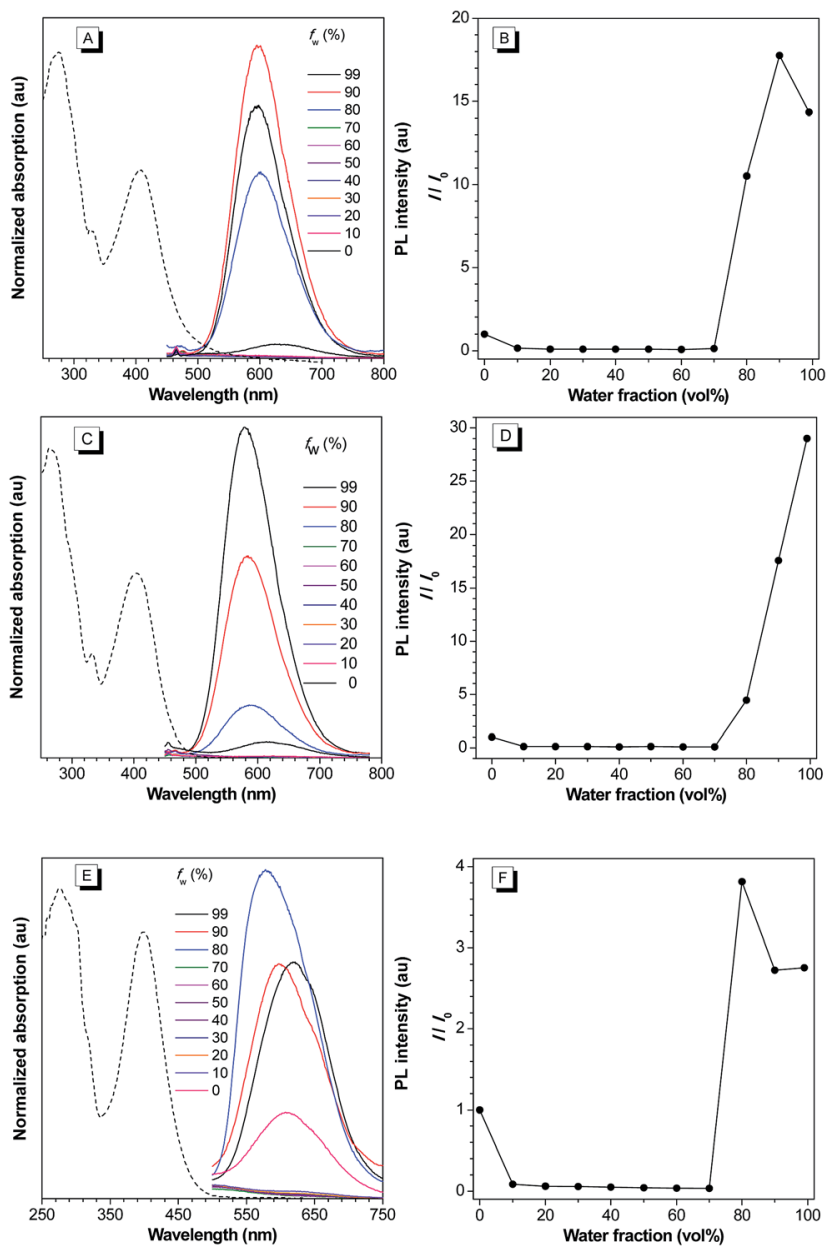

Fig. 2 (A, C, and E) Normalized UV-vis absorption spectra of 2a, 2b, and $2 c$ THF (dashed line); PL spectra of $2 a, 2 b$, and $2 c$ in THF and THF/ water mixture with different water fractions $\left(f_{\mathrm{w}}\right) \cdot(\mathrm{B}, \mathrm{D}$, and $\mathrm{F})$ Plots of relative maximum emission intensity $\left(I / I_{0}\right)$ of $2 a, 2 b$, and $2 c$ versus the solvent composition of THF/water mixture. [2a] $=[2 \mathrm{~b}]=[2 \mathrm{c}]=10 \mu \mathrm{M}$. For $2 \mathrm{a}, \lambda_{\mathrm{ex}}=409 \mathrm{~nm}$. For $2 \mathrm{~b}, \lambda_{\mathrm{ex}}=402 \mathrm{~nm}$. For $2 \mathrm{c}, \lambda_{\mathrm{ex}}=400 \mathrm{~nm}$. 
content. Successively, the emission intensity of 2a showed a little decrease at $99 \%$ water fraction, which can be possibly due to the fast decrease in the solubility leading to the formation of amorphous aggregates with lower fluorescence efficiency. ${ }^{16}$ To verify that the AIE phenomenon is caused by the restriction of intramolecular motion, we measured the emission of 2a in polar solvents of ethanol and glycerol with low $(\eta=1.2 \mathrm{mPa} \mathrm{S})$ and high viscosity $(\eta=945 \mathrm{mPa} \mathrm{S})$, respectively. ${ }^{17}$ A 158-fold emission enhancement at $600 \mathrm{~nm}$ was observed in glycerol than that in ethanol, which clearly verified that the AIE phenomenon is caused by the restriction of intramolecular motion (Fig. S9†) ${ }^{18}$ Similar to $2 \mathbf{a}$, both $\mathbf{2 b}$ and $2 \mathbf{c}$ first showed a decrease in the fluorescence intensity with the increase in the water fraction $\left(f_{\mathrm{w}}\right)$ from 0 to $70 \%$, and then exhibited significant emission enhancements as $f_{\mathrm{w}}$ increased from 70 to $99 \%$ and $80 \%$, respectively. We then measured the photophysical properties of $\mathbf{2 a - c}$ in the film state (Table $\mathrm{S} 1 \dagger$ ). Compared to those in the THF solution state, $\mathbf{2 a}, \mathbf{2} \mathbf{b}$, and $\mathbf{2 c}$ in the film state, respectively, exhibited 20, 18.4, and 12-fold increase in the fluorescence quantum yields $\left(\Phi_{\mathrm{f}}\right), 3.4,8.8$, and 7.0-fold increase in the fluorescence lifetime $(\tau), 2.5,2.1$, and 1.7-fold increase in the radiative decay rates $\left(k_{\mathrm{r}}\right)$, and 3.6, 9.2, and 7.6-fold decrease in the nonradiative decay rates $\left(k_{\mathrm{nr}}\right)$. They also exhibited large Stokes shifts of 8424, 8668, and $8607 \mathrm{~cm}^{-1}$ in the film state, respectively. The excellent emission efficiency enhancement and large Stokes shifts in the aggregated state can greatly favor their applications in bioimaging.

We next examined the photooxidative transformation of dihydro-2-azafluorenone 1 into 2-azafluorenone 2. Upon irradiation at $365 \mathrm{~nm}$ using a hand-held UV lamp, a gradually increased fluorescence was observed for $\mathbf{1 a}$ in aqueous solution (Fig. 3A
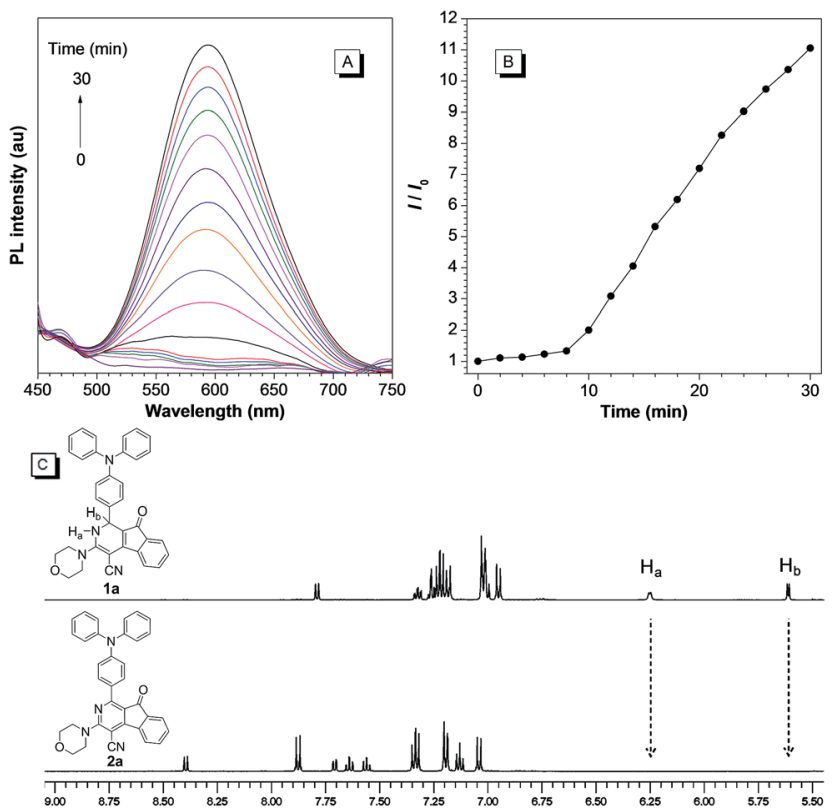

Fig. 3 (A) The PL spectra of 1a in DMSO/water mixture with $99 \%$ water fraction under irradiation at $365 \mathrm{~nm}$ for $0-30 \mathrm{~min}$. $\lambda_{\mathrm{ex}}=409 \mathrm{~nm}$. (B) Plot of relative $\mathrm{PL}$ intensity $\left(/ / /_{0}\right)$ of $1 \mathrm{a}$ at $600 \mathrm{~nm}$ versus the irradiation time. (C) The stacking ${ }^{1} \mathrm{H}$ NMR spectra of $1 \mathrm{a}$ and $2 \mathrm{a}$. and B), indicating that 1a can efficiently undergo photooxidative transformation to afford AIE-active 2a. Various water soluble oxidants, such as $\mathrm{H}_{2} \mathrm{O}_{2}, t$-BuOOH, $\mathrm{NaOCl}$, sodium persulfate, and potassium peroxymonosulfate, have also been tested for the oxidation of 1a into 2a under dark conditions at room temperature; however, all of them can not promote this transformation (Fig. S10 $\dagger$ ). The photooxidative transformation was also verified by the UV-vis absorption spectra changes of 1a, in which the maximum absorption wavelength progressively shifted from $530 \mathrm{~nm}$ to a shorter wavelength at $413 \mathrm{~nm}$ (Fig. S11 $\dagger$ ). Moreover, the stacking ${ }^{1} \mathrm{H}$ NMR spectra of $1 \mathrm{a}$ and $2 \mathrm{a}$ showed that the $\mathrm{H}_{\mathrm{a}}$ and $\mathrm{H}_{\mathrm{b}}$ in 1a (peaks at 6.25 and $5.61 \mathrm{ppm}$, respectively) completely disappeared in 2a (Fig. 3C), which clearly verified the proposed photooxidative dehydrogenation mechanism. Similar to $\mathbf{1 a}$, compounds $\mathbf{1 b}$ and $\mathbf{1 c}$ also exhibited the fast light-up fluorescence and blue-shifted absorption under UV light irradiation (Fig. S12-S15†), which indicates their smooth transformation to 2b and 2c via the photooxidative reaction.

We then used 1a as a photoactivatable probe for live-cell imaging. Based on MTT assay, the cytotoxicity of 1a and 2a was first evaluated for lung cancer HCC827, A549 cells, and normal lung HLF cells. As shown in Fig. S16, $\uparrow$ no significant change in the cell viability was observed even when a high concentration of $100 \mu \mathrm{M}$ of $1 \mathrm{a}$ or $2 \mathrm{a}$ was present in the culture medium, which suggests that 1a or $2 \mathbf{a}$ has very low cytotoxicity. Based on 1a, we then conducted the photoactivatable imaging experiment in the lung cancer HCC827 cells. After incubation at $37^{\circ} \mathrm{C}$ for $15 \mathrm{~min}$,
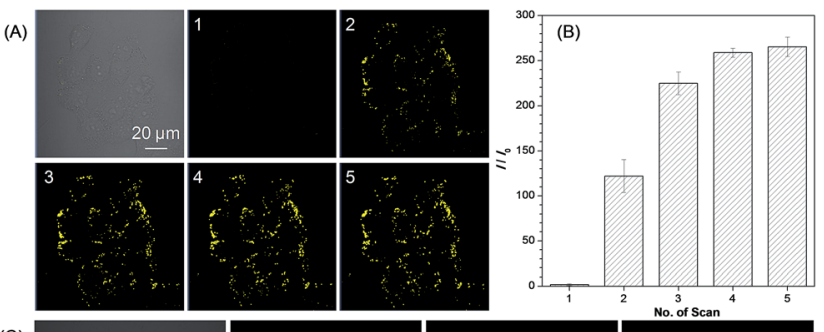

(C)

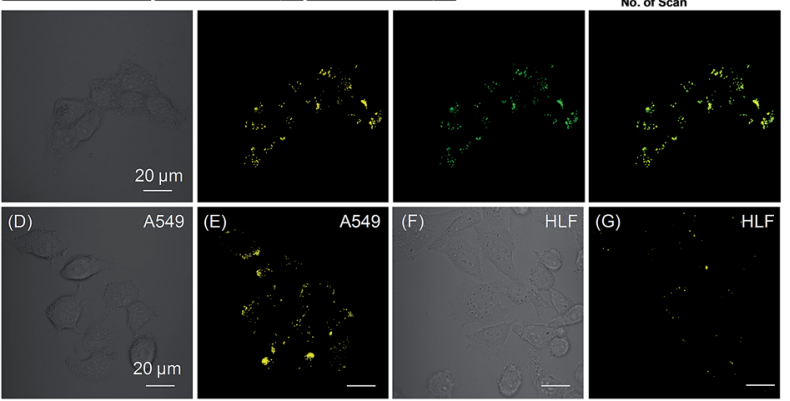

Fig. 4 (A) Bright field and fluorescence images of live HCC827 cells obtained under white light illumination and increasing scans at $405 \mathrm{~nm}$ with $1 \%$ laser power (the number of scans are shown in the upper left corner and the scanning rate was $22.4 \mathrm{~s}$ per frame). (B) Plot of fluorescence enhancement $\left(I / I_{0}\right)$ of $\mathrm{HCC} 827$ cells with the increasing scans at $405 \mathrm{~nm}$. (C) Bright field and fluorescence images of the HCC827 cells stained with 1a after photoactivation (yellow), BODIPY493/503 (green), and the merged image. (D) Bright field, and (E) fluorescence images of the live A549 cells stained with 1a after photoactivation. (F) Bright field, and (G) fluorescence images of live HLF cells stained with $1 \mathrm{a}$ after photoactivation by irradiation. [1a] $=20 \mu \mathrm{M}$. Scale bar $=20 \mu \mathrm{m}$. 
1a can be efficiently uptaken by HCC827 cells and a very fast light-up process (less than $2 \mathrm{~min}$ ) was observed via irradiation at $405 \mathrm{~nm}$ with very mild irradiation of only $1 \%$ laser power (Fig. 4A). Through statistically analyzing the increased fluorescence intensity of 1a in HCC827 cells, an excellent light-up ratio of 265-fold was obtained (Fig. 4B). The co-localization experiment with lipid dye BODIPY493/503 green was then conducted to test the specificity of 1a for LDs (Fig. 4C). The results show that photoactivated 1a could co-localize well with BODIPY493/ 503 green with a high overlap coefficient of 0.99 (Fig. S17 $\dagger$ ). Through light irradiation at $405 \mathrm{~nm}$, a fast light-up process of 1a was also observed in the A549 cells (Fig. 4D, E and S18 $\dagger$ ), and its specificity for LDs was also verified by co-staining with

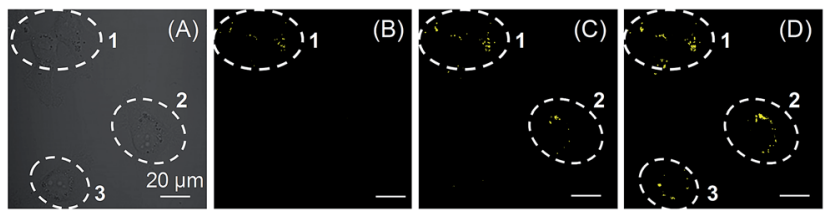

Fig. 5 (A) Bright field of HCC827 cells. (B-D) Sequential photoactivation of $\mathrm{HCC} 827$ cells (cells 1, 2, and 3) by irradiation at $405 \mathrm{~nm}$ $(0.2 \%$ laser power). Dashed lines indicate the periphery of cells. [1a] $=$ $20 \mu \mathrm{M}$. Scale bar $=20 \mu \mathrm{m}$.

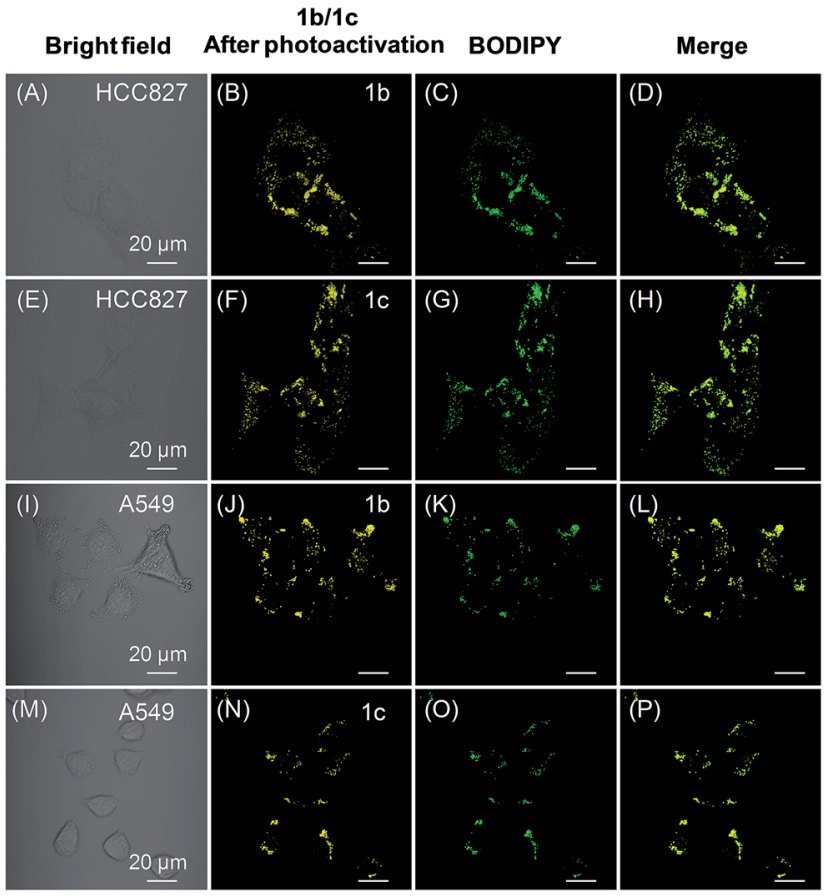

Fig. 6 (A and E) Bright-field images of HCC827 cells. (B and F) Fluorescence images of $\mathrm{HCC} 827$ cells from $1 \mathrm{~b}$ and $1 \mathrm{c}$ after photoactivation, respectively. ( $C$ and $G$ ) Fluorescence images of HCC827 cells from BODIPY493/503 green. (D and H) The merged images. (I and M) Bright-field images of A549 cells. ( $\mathrm{J}$ and N) Fluorescence images of A549 cells from $1 b$ and $1 c$ after photoactivation, respectively. ( $K$ and $O$ ) Fluorescence images of A549 cells from BODIPY493/503 green. ( $L$ and P) The merged images. Both $1 \mathrm{~b}$ and $1 \mathrm{c}$ were photoactivated through irradiation at $405 \mathrm{~nm}$ for $3 \mathrm{~min}$ (1\% laser power). [1b] $=[1 \mathrm{c}]=20 \mu \mathrm{M}$. Scale bar $=20 \mu \mathrm{m}$.
BODIPY493/503 green (Fig. S19 $\dagger$ ). Compared to lung cancer HCC827 and A549 cells, only few LDs were observed in the normal lung HLF cells by photoactivated 1a (Fig. 4F and G). The much larger number of LDs in the lung cancer HCC827 and A549 cells is probably due to their faster growing rate compared with normal lung HLF cells. ${ }^{3}$ This experiment suggests that 1a as a photoactivatable and LDs-specific probe can be used to discriminate between the cancer and normal cells through their different expression levels for LDs.

Light as an external trigger is a valuable and easily controllable tool with high spatial and temporal accuracy. As shown in Fig. 5, sequential photoactivation of 1a in selected HCC827 cells can be achieved in a multicellular environment. This experiment suggests that 1a as a photoactivatable probe is potential to monitor the dynamic events of LDs in a complex biological sample.

We also tested the targeting specificity and photoactivatable imaging ability of $\mathbf{1 b}-\mathbf{c}$ for LDs in the lung cancer HCC827 and A549 cells. Through irradiation at $405 \mathrm{~nm}$ with 1\% laser power, fast light-up processes were observed for both $\mathbf{1 b}$ and $\mathbf{1 c}$ in HCC827 and A549 cells, and maximum emission intensities could be achieved in 3 min (Fig. S20-S23†). The co-localization experiment with lipid dye BODIPY493/503 green clearly showed that $\mathbf{1 b}$ and 1c can also be used for LDs-specific photoactivatable imaging (Fig. 6). In HCC827 cells, the overlap coefficients for $\mathbf{1 b}$ and 1c with lipid dye BODIPY493/503 green are 0.99 and 0.98, respectively; whereas in A549 cells, the overlap coefficients for $\mathbf{1 b}$ and 1c with BODIPY493/503 green are 0.97 and 0.99, respectively.

\section{Conclusions}

In conclusion, we have developed photoactivatable and LDs-specific probes based on dihydro-2-azafluorenones, which can easily undergo photooxidative dehydrogenation reaction to afford 2-azafluorenones with typical AIE properties. Even with different amine substituents, dihydro-2-azafluorenones are generally applicable for LDs-specific imaging in live cells with an excellent photoactivation efficiency and high signal-to-noise ratio. They can also be used for the sequential photoactivation of selected cells in a multicellular environment. Moreover, they can efficiently discriminate between lung cancer and normal lung cells through their different expression levels for LDs. Benefiting from the advantages of absence of self-quenching in the aggregated state, easy preparation, fast cell uptake, low cytotoxicity, and excellent photoactivation efficiency, the photoactivatable AIE probes developed in this study are expected to have broad applications in the biological studies of LDs.

\section{Acknowledgements}

This work was financially supported by China Postdoctoral Science Foundation Grant (2015M580716 and 2016T90778), the Key Project of the Ministry of Science and Technology of China (2013CB834702), National Science Foundation of China (51620105009 and 21602063), Natural Science Foundation of Guangdong Province (2016A030313852 and 2016A030312002), Fundamental Research Funds for the Central Universities (2015ZY013 and 2015ZZ104), Innovation and Technology 
Commission of Hong Kong (ITC-CNERC14SC01), and Guangdong Innovative Research Team Program (201101C0105067115).

\section{Notes and references}

1 (a) S. O. Olofsson, P. Bostrom, L. Andersson, M. Rutberg, J. Perman and J. Boren, Biochim. Biophys. Acta, Mol. Cell Biol. Lipids, 2009, 1791, 448-458; (b) S. Martin and R. G. Parton, Nat. Rev. Mol. Cell Biol., 2006, 7, 373-378.

2 (a) Y. Miyanari, K. Atsuzawa, N. Usuda, K. Watashi, T. Hishiki, M. Zayas, R. Bartenschlager, T. Wakita, M. Hijikata and K. Shimotohno, Nat. Cell Biol., 2007, 9, 1089-1097; (b) P. T. Bozza and J. P. Viola, Prostaglandins, Leukotrienes Essent. Fatty Acids, 2010, 82, 243-250; (c) Y. Guo, T. C. Walther, M. Rao, N. Stuurman, G. Goshima, K. Terayama, J. S. Wong, R. D. Vale, P. Walter and R. V. Farese, Nature, 2008, 453, 657-661.

3 (a) H. Abramczyk, J. Surmacki, M. Kopec, A. K. Olejnik, K. Lubecka-Pietruszewska and K. Fabianowska-Majewska, Analyst, 2015, 140, 2224-2235; (b) L. Tirinato, C. Liberale, S. Di Franco, P. Candeloro, A. Benfante, R. La Rocca, L. Potze, R. Marotta, R. Ruffilli, V. P. Rajamanickam, M. Malerba, F. De Angelis, A. Falqui, E. Carbone, M. Todaro, J. P. Medema, G. Stassi and E. Di Fabrizio, Stem Cells, 2015, 33, 35-44; (c) C. R. Santos and A. Schulze, FEBS J., 2012, 279, 2610-2623; (d) R. Chowdhury, B. Jana, A. Saha, S. Ghosh and K. Bhattacharyya, Med. Chem. Commun., 2014, 5, 536.

4 (a) F. M. Raymo, Phys. Chem. Chem. Phys., 2013, 15, 1484014850; (b) W. H. Li and G. Zheng, Photochem. Photobiol. Sci., 2012, 11, 460-471; (c) C. Brieke, F. Rohrbach, A. Gottschalk, G. Mayer and A. Heckel, Angew. Chem., Int. Ed., 2012, 51, 8446-8476; (d) Q. Shao and B. Xing, Chem. Soc. Rev., 2010, 39, 2835-2846; (e) M. J. Rust, M. Bates and X. Zhuang, Nat. Methods, 2006, 3, 793-796.

5 N. Kory, A. R. Thiam, R. V. Farese Jr and T. C. Walther, Dev. Cell, 2015, 34, 351-363.

6 (a) R. I. MacDonald, J. Biol. Chem., 1990, 265, 13533-13539; (b) A. Reisch and A. S. Klymchenko, Small, 2016, 12, 19681992; (c) J. M. Swiecicki, F. Thiebaut, M. Di Pisa, S. Gourdin-Bertin, J. Tailhades, C. Mansuy, F. Burlina, S. Chwetzoff, G. Trugnan, G. Chassaing and S. Lavielle, Sci. Rep., 2016, 6, 20237.

7 (a) Y. Zhang, S. Swaminathan, S. Tang, J. Garcia-Amoros, M. Boulina, B. Captain, J. D. Baker and F. M. Raymo, J. Am. Chem. Soc., 2015, 137, 4709-4719; (b) M. K. Lee, P. Rai, J. Williams, R. J. Twieg and W. E. Moerner, J. Am. Chem. Soc., 2014, 136, 14003-14006; (c) T. Kobayashi, T. Komatsu, M. Kamiya, C. Campos, M. Gonzalez-Gaitan, T. Terai, K. Hanaoka, T. Nagano and Y. Urano, J. Am. Chem. Soc., 2012, 134, 11153-11160; (d) Z. Yu, L. Y. Ho and Q. Lin, J. Am. Chem. Soc., 2011, 133, 11912-11915; (e) S. J. Lord, N. R. Conley, H.-l. D. Lee, R. Samuel, N. Liu, R. J. Twieg and W. E. Moerner, J. Am. Chem. Soc., 2008, 130, 92049205; $(f)$ N. Gagey, P. Neveu, C. Benbrahim, B. Goetz, I. Aujard, J.-B. Baudin and L. Jullien, J. Am. Chem. Soc., 2007, 129, 9986-9998.
8 (a) S. Daemen, M. A. M. J. van Zandvoort, S. H. Parekh and M. K. C. Hesselink, Molecular Metabolism, 2016, 5, 153-163; (b) J. Zhai, Y. Zhang, C. Yang, Y. Xu and Y. Qin, Analyst, 2014, 139, 52-54; (c) E. Kim, S. Lee and S. B. Park, Chem. Commun., 2012, 48, 2331-2333; (d) S. Rabhi, I. Rabhi, B. Trentin, D. Piquemal, B. Regnault, S. Goyard, T. Lang, A. Descoteaux, J. Enninga and L. Guizani-Tabbane, PLoS One, 2016, 11, e0148640; (e) J. H. Lee, J. H. So, J. H. Jeon, E. B. Choi, Y. R. Lee, Y. T. Chang, C. H. Kim, M. A. Bae and J. H. Ahn, Chem. Commun., 2011, 47, 7500-7502; (f) A. Sharma, S. Umar, P. Kar, K. Singh, M. Sachdev and A. Goel, Analyst, 2016, 141, 137-143; $(g)$ J. Spandl, D. J. White, J. Peychl and C. Thiele, Traffic, 2009, 10, 1579-1584; (h) A. B. Neef and C. Schultz, Angew. Chem., Int. Ed., 2009, 48, 1498-1500; (i) D. Eggert, K. Rosch, R. Reimer and E. Herker, PLoS One, 2014, 9, e102511. 9 X. Lim, Nature, 2016, 531, 26-28.

10 (a) J. Mei, Y. Hong, J. W. Lam, A. Qin, Y. Tang and B. Z. Tang, Adv. Mater., 2014, 26, 5429-5479; (b) J. Mei, N. L. Leung, R. T. Kwok, J. W. Lam and B. Z. Tang, Chem. Rev., 2015, 115, 11718-11940; (c) F. Bu, R. Duan, Y. Xie, Y. Yi, Q. Peng, R. $\mathrm{Hu}, \mathrm{A}$. Qin, Z. Zhao and B. Z. Tang, Angew. Chem., Int. Ed., 2015, 54, 14492-14497; (d) N. L. Leung, N. Xie, W. Yuan, Y. Liu, Q. Wu, Q. Peng, Q. Miao, J. W. Lam and B. Z. Tang, Chem.-Eur. J., 2014, 20, 15349-15353; (e) Q. Li and Z. Li, Sci. China: Chem., 2015, 58, 1800-1809.

11 (a) D. Ding, K. Li, B. Liu and B. Z. Tang, Acc. Chem. Res., 2013, 46, 2441-2453; (b) R. T. Kwok, C. W. Leung, J. W. Lam and B. Z. Tang, Chem. Soc. Rev., 2015, 44, 4228-4238; (c) J. Liang, B. Z. Tang and B. Liu, Chem. Soc. Rev., 2015, 44, 2798-2811; (d) X. Gu, E. Zhao, T. Zhao, M. Kang, C. Gui, J. W. Lam, S. Du, M. M. Loy and B. Z. Tang, Adv. Mater., 2016, 28, 5064-5071; (e) X. Gu, E. Zhao, J. W. Lam, Q. Peng, Y. Xie, Y. Zhang, K. S. Wong, H. H. Sung, I. D. Williams and B. Z. Tang, Adv. Mater., 2015, 27, 7093-7100.

12 (a) Z. Wang, C. Gui, E. Zhao, J. Wang, X. Li, A. Qin, Z. Zhao, Z. Yu and B. Z. Tang, ACS Appl. Mater. Interfaces, 2016, 8, 10193-10200; (b) E. Wang, E. Zhao, Y. Hong, J. W. Y. Lam and B. Z. Tang, J. Mater. Chem. B, 2014, 2, 2013; (c) M. Kang, X. Gu, R. T. Kwok, C. W. Leung, J. W. Lam, F. Li and B. Z. Tang, Chem. Commun., 2016, 52, 5957-5960.

13 (a) G. R. Heintzelman, J. L. Bullington and K. C. Rupert, WO2005042500A1, 2005; (b) T. Landmesser, A. Linden and H.-J. Hansen, Helv. Chim. Acta, 2008, 91, 265-284.

14 CCDC 1497612 contains the supplementary crystallographic data for this paper.

15 R. R. Hu, E. Lager, A. Aguilar-Aguilar, J. Z. Liu, J. W. Y. Lam, H. H. Y. Sung, I. D. Williams, Y. C. Zhong, K. S. Wong, E. Pena-Cabrera and B. Z. Tang, J. Phys. Chem. C, 2009, 113, 15845-15853.

16 A. Shao, Y. Xie, S. Zhu, Z. Guo, S. Zhu, J. Guo, P. Shi, T. D. James, H. Tian and W. H. Zhu, Angew. Chem., Int. Ed., 2015, 54, 7275-7280.

17 M. A. Haidekker, T. P. Brady, D. Lichlyter and E. A. Theodorakis, Bioorg. Chem., 2005, 33, 415-425.

18 Y. Hong, J. W. Y. Lam and B. Z. Tang, Chem. Commun., 2009, 4332-4353. 